\title{
Redes interorganizacionais nas Comunidades que Sustentam a Agricultura no Distrito Federal
}

\author{
Interorganizational networks in Communities Supported Federal \\ District Agriculture
Redes interorganizacionales en las Comunidades que Apoyan la Agricultura en el Distrito Federal

\author{
Joelma Melo da Silva ${ }^{1}$ \\ Maria Júlia Pantoja ${ }^{1}$ \\ Sérgio Ricardo Franco Vieira ${ }^{1}$
}

Recebido em: 08/05/2020; revisado e aprovado: 20/03/2021; aceito: 01/04/2021

DOI: htttp://dx.doi.org/10.20435/inter.v22i3.3055

\begin{abstract}
Resumo: A agricultura familiar vem passando por significativas transformações que têm impulsionado a criação de novas formas organizativas, entre elas as Comunidades que Sustentam a Agricultura (CSA), um modelo de economia associativa e comunitária. Buscou-se identificar como as redes interorganizacionais de compartilhamento e de comprometimento podem influenciar na manutenção e no desenvolvimento do modelo produtivo das CSAs no Distrito Federal. Para isso, foi realizada uma revisão bibliográfica e análise documental. Posteriormente, foi aplicado um questionário aos agricultores, e os dados foram analisados por meio do software UCINET. A ferramenta NETDRAW foi usada para gerar os gráficos das redes. Os resultados encontrados permitem inferir que a rede de compartilhamento parece coesa, o que pode influenciar na capacidade de gerar valor e fomentar a aprendizagem organizacional. Além disso, a rede de comprometimento registrou os maiores índices de densidade e coesão, sinalizando grau de conformidade do grupo em relação aos princípios da CSA, podendo influir nos processos de inovação, na produtividade e no atendimento aos coagricultores. Inferiu-se que o modelo produtivo de CSA no Distrito Federal pode ser uma alternativa viável para o desenvolvimento sustentável da agricultura familiar. Para estudos futuros, recomenda-se a inclusão da rede de confiança e ampliação da amostra, incorporando atores de comércios locais e órgãos públicos onde se localizam os pontos de convivência das CSAs, bem como empresas de assistência técnica, os quais podem estar envolvidos com as CSAs.
\end{abstract}

Palavras-chave: agricultura familiar; redes interorganizacionais; comprometimento; compartilhamento; desenvolvimento.

Abstract: Family farming has undergone significant transformations that have led to the creation of new organizational forms, including the Community Supported Agriculture (CSA), a model of associative and community economics. We sought to identify how interorganizational networks of sharing and commitment can influence the maintenance and development of the productive model of CSAs in the Federal District. For this, a bibliographic review and document analysis was carried out. Subsequently, a questionnaire was applied to the farmers, and the data were analyzed using the UCINET software. The NETDRAW tool was used to generate the graphics of the networks. The results found allow us to infer that the sharing network seems cohesive, which can influence the ability to generate value and foster organizational learning. In addition, the commitment network recorded the highest rates of density and cohesion, signaling the group's degree of compliance with the CSA principles, which can influence innovation processes, productivity, and service to co-farmers. It was inferred that the productive model of CSA in the Federal District can be a viable alternative for the sustainable development of family farming. For future studies, it is recommended to include the trust network and expand the sample, incorporating actors from local businesses and public bodies where the CSAs are located, as well as technical assistance companies, which may be involved with the CSAs.

Keywords: family farming; interorganizational networks; commitment; sharing; development.

Resumen: La agricultura familiar ha sufrido importantes transformaciones que han dado lugar a la creación de nuevas formas organizativas, entre ellas las Comunidades que Apoyan la Agricultura (CSA), modelo de economía asociativa y comunitaria. Buscamos identificar cómo las redes interorganizacionales de intercambio y compromiso pueden influir en el mantenimiento y desarrollo del modelo productivo de CSA en el Distrito Federal. Para ello se realizó una revisión bibliográfica y análisis documental. Posteriormente, se aplicó un

\footnotetext{
${ }^{1}$ Universidade de Brasília (UnB), Brasília, Distrito Federal, Brasil.
} 
cuestionario a los agricultores y se analizaron los datos mediante el software UCINET. Se utilizó la herramienta NETDRAW para generar los gráficos de las redes. Los resultados encontrados permiten inferir que la red de intercambio parece cohesionada, lo que puede influir en la capacidad de generar valor y fomentar el aprendizaje organizacional. Además, la red de compromiso registró las tasas más altas de densidad y cohesión, lo que indica el grado de cumplimiento del grupo con los principios de CSA, que pueden influir en los procesos de innovación, la productividad y el servicio a los coagricultores. Se infirió que el modelo productivo de CSA en el Distrito Federal puede ser una alternativa viable para el desarrollo sustentable de la agricultura familiar. Para futuros estudios se recomienda la inclusión de la red de confianza y ampliación de la muestra, incorporando actores de las empresas locales y organismos públicos donde se ubican los puntos de contacto de las CSA, así como empresas de asistencia técnica, que puedan estar involucradas con las CSA.

Palabras clave: agricultura familiar; redes interorganizacionales; comprometimiento; intercambio; desarrollo.

\section{INTRODUÇÃO}

É possível observar a crescente preocupação da sociedade civil acerca de assuntos relacionados à preservação de recursos naturais, alimentação saudável, produção sustentável, segurança alimentar e nutricional, desenvolvimento local, entre outros. Nesse sentido, a produção da agricultura familiar, que busca produzir de forma diversificada, agroecológica e sustentável, tem contribuído para que alimentos saudáveis cheguem à mesa das famílias (CONFEDERAÇÃO NACIONAL DOS TRABALHADORES E TRABALHADORAS NA AGRICULTURA FAMILIAR DO BRASIL [CONTRAF-BRASIL], 2018), ainda que nem todo agricultor familiar conduza sua produção de forma agroecológica. Além disso, a agricultura familiar responde por sete em cada dez postos de trabalho no campo (BRASIL, 2018), favorecendo o desenvolvimento local e a permanência do jovem do campo no campo.

Em busca do seu fortalecimento, a agricultura familiar vem se organizando ao longo do tempo em diversas configurações. Martins (2017) afirma que as pessoas estão se organizando em vários lugares do mundo e formando comunidades em torno de alimentos produzidos localmente, como é o caso da Comunidade que Sustenta a Agricultura (CSA), que, de acordo com CSA BRASÍLIA (2018), é uma organização informal, estabelecida com base no compromisso entre agricultor e coagricultor e orientada por valores e princípios característicos, em que o consumidor é coagricultor, ao financiar a produção ao longo de seis ou doze meses e receber os produtos semanalmente em um ponto de convivência próximo de sua residência, podendo participar de algumas etapas do processo produtivo, tendo a oportunidade de entrar em contato direto com a terra.

Essas relações de vínculos econômicos, sociais e culturais vivenciados pelos agricultores e seus coagricultores sugerem, entre outros aspectos, uma busca de agregação de valor relacional e transacional. Nesse sentido, surge o debate sobre os aspectos inerentes às relações informais estabelecidas e mantidas entre os coagricultores para a criação e o desenvolvimento das CSAs. Considera-se que "As relações sociais em que cada indivíduo está inserido podem ser vistas como uma rede" (NEIVA; PANTOJA, 2008, p. 11), uma vez que "[...] nas ciências sociais e psicológicas, redes sociais são formas específicas de interação entre indivíduos, redes urbanas, redes organizacionais, movimentos sociais, entre outras" (VIEIRA, 2008, p. 4), em que, apesar da ampla possibilidade de conceituação, "[...] há um sentido predominante: a ideia de ligação, laço e integração" (VIEIRA, 2008, p. 4).

Tendo em vista o crescente interesse de cientistas e gestores em compreender como os atores, nesse caso, as organizações, estabelecem relações e interagem entre si, configurando uma rede social (RIBEIRO; BASTOS, 2011), entende-se que esta pesquisa poderá contribuir não 
só com gestores e pesquisadores, como também com a comunidade em geral. Além disso, o tema redes interorganizacionais é foco de interesse de formuladores de políticas públicas, que buscam no associativismo, especialmente de pequenas e médias empresas, um meio de promover o desenvolvimento local (CUNHA; PASSADOR; PASSADOR, 2012).

Diante do exposto, o objetivo desta pesquisa consiste em mapear e analisar as redes interorganizacionais de compartilhamento de conhecimentos, informações, ideias e boas práticas e a rede de comprometimento, com os princípios e valores norteadores das CSAs, a fim de identificar como elas influenciam na manutenção e no desenvolvimento dessas redes. Para tanto, buscou-se responder: qual é a configuração da Rede de Compartilhamento de Conhecimento, Informação, Ideias e Boas Práticas das CSAs do Distrito Federal (DF)? Quais CSAs são vistas como referência pelas demais CSAs na adoção dos princípios norteadores de uma CSA? De que maneira essas redes de compartilhamento e comprometimento podem influenciar na manutenção e no desenvolvimento dessas comunidades?

O artigo está organizado em quatro seções, além desta introdução. A segunda seção apresenta o referencial teórico com uma breve contextualização da agricultura familiar e das Comunidades que Sustentam a Agricultura (CSA) no Distrito Federal, bem como uma breve discussão sobre os conceitos e as medidas de análise de redes informais interorganizacionais. A terceira seção traz a metodologia utilizada nesta pesquisa. Na quarta seção, são apresentados os resultados e as discussões e, na quinta e última seção, as considerações finais, seguidas das referências.

\section{REFERENCIAL}

\subsection{Agricultura familiar e as CSAs no Distrito Federal}

Como principal característica da agricultura familiar, destaca-se a preferência para a mão de obra da própria família em sua atividade produtiva, inclusive na gestão do empreendimento, que ocorre de maneira direta e presencial, por meio de algum membro familiar (GUANZIROLI; BUAINAIN; DI SABBATO, 2012). Entretanto, entre os anos 1960 e 1970, a agricultura brasileira passou por diversas transformações em busca de modernização (PADUA; SCHLINDWEIN; GOMES, 2013) com vistas à exportação da produção, o que desencadeou a marginalização de agricultores familiares que não conseguiram acompanhar o desenvolvimento estimulado pelo Estado com incentivos para se produzir culturas de commodities visando à exportação, a fim de que assim se impulsionasse a economia do país, levando-os à marginalidade em níveis social, econômico e ambiental e provocando o êxodo rural, como afirma Caume (2003 apud PADUA; SCHLINDWEIN; GOMES, 2013).

Já em meados de 1980 e 1990, devido a uma crescente preocupação com questões ambientais, a agricultura familiar passou a ser considerada um importante agente para a construção de um desenvolvimento rural sustentável para o país, por ter um cultivo diversificado, adotar práticas de cultivo ecologicamente mais equilibradas, fazer uso reduzido de insumos industriais, além de ser um gerador de renda e, por consequência, reduzir o êxodo rural (PADUA; SCHLINDWEIN; GOMES, 2013). No entanto, até os anos 2000, a agricultura familiar era vista como "pequena produção", "pequena produção de subsistência" e até mesmo como "depósito e reserva de mão de obra", como explicam Guanziroli, Buainain e Di Sabbato (2012).

Outro fator importante no âmbito da agricultura familiar e que merece especial atenção é a comercialização da produção, tema abordado por Verano e Medina (2019) que, referenciando-se em Wilkinson (2003), chamam a atenção para o caráter excludente da 
comercialização via mercados convencionais, uma vez que estes exigem organização logística, padronização da qualidade e regularidade da oferta, pois, mesmo que essa possibilidade de comercialização tenha sido ampliada com o fortalecimento das grandes redes de supermercados, tais requisitos não condizem com a realidade da maioria dos agricultores familiares.

Diante disso, se, por um lado, as condições sociais e de mercado convencional não são tão favoráveis, por outro lado, Martins (2017) afirma que as pessoas estão se organizando em diversos lugares do mundo e formando comunidades em torno de alimentos produzidos localmente. Esse tipo de organização refere-se ao movimento CSA, que se caracteriza por ser:

[...] um modelo de um trabalho conjunto entre produtores de alimentos orgânicos e consumidores: um grupo fixo de consumidores se compromete por um ano (em geral) a cobrir o orçamento anual da produção agrícola. Em contrapartida os consumidores recebem os alimentos produzidos pelo sítio ou fazenda sem outros custos adicionais. Desta forma o produtor sem a pressão do mercado e do preço, pode se dedicar de forma livre a sua produção. E os consumidores recebem produtos de qualidade, sabendo quem os produz e aonde são produzidos [...]. (CSA BRASIL, 2015).

Ainda segundo CSA BRASIL (2015), essa é uma nova forma de relação social e econômica, em que agricultores e coagricultores promovem uma ação conjunta para a produção de alimentos, configurando-se uma economia associativa em que dividem tarefas de apoio da comunidade, buscando não apenas reverter o fluxo do êxodo rural, mas promover a autoestima das pessoas interessadas em lidar com a terra (CSA BRASíLIA, 2018).

Segundo CSA Brasília (2018), na ocasião do Fórum Mundial Social realizado em Porto Alegre, Rio Grande do Sul (RS), em 2011, o conceito da CSA foi apresentado como favorito e com potencial de futuro no Brasil, surgindo, em São Paulo, a primeira CSA brasileira, denominada CSA Demétria. Já em 2014, a Associação Comunitária CSA Brasil foi fundada, com vistas ao apoio à formação de CSA, divulgação de informações inerentes à CSA e criação da Rede CSA Brasil.

As características da agricultura familiar e o processo de criação e desenvolvimento das CSAs levam a crer que o desenvolvimento e o fortalecimento da agricultura familiar podem partir de dentro e entre a própria categoria em parceria com a comunidade local, pois, como afirma Dorsa (2019), referenciando Martín (1999), a partir do protagonismo do indivíduo e do enfoque social na comunidade, município ou região, com base em iniciativas individuais ou coletivas de base econômica familiar, esse tipo de desenvolvimento, chamado de endógeno, representa uma estratégia que maximiza a economia e proporciona maior interação social, contribuindo para a construção de um tecido social local, municipal e regional.

Asato et al. (2019) explicam o desenvolvimento como a ação ou o efeito de se desenvolver, de remover o que envolve em busca do crescimento, do aumento e do desabrochar de algo. Oliveira e Liboni (2018) trazem que fatores endógenos ou exógenos determinam o curso e a direção do desenvolvimento e, referenciando-se em Garofoli (2002), explicam que, enquanto o processo de desenvolvimento endógeno assegura a autonomia na transformação da economia local, o exógeno depende da intervenção de atores econômicos externos.

Diante do exposto, a análise das redes informais interorganizacionais das CSAs apresentase como uma importante ferramenta de análise para que os agricultores, que são também os gestores, conheçam mais detalhadamente a estrutura, as potencialidades e os pontos que merecem atenção na rede em que estão inseridos, de forma que possam desenvolver estratégias mais adequadas à sua realidade e às demandas locais, a fim de promover o desenvolvimento da comunidade de forma sustentável. 


\subsection{Medidas de análise em redes sociais}

A análise de redes se caracteriza por ser um conjunto de técnicas utilizadas para proporcionar aos interessados, nos resultados, a verificação dos conjuntos de relações e o padrão das conexões entre os agentes (DE ROLT; DIAS; PEÑA, 2017). Sendo assim, Vieira (2008) aponta para os indicadores macroestruturais, como tamanho, densidade, distância geodésica, diâmetro e índice de coesão, ao passo que Ribeiro e Bastos (2011) chamam atenção também para os indicadores microestruturais, como centralidade de grau e centralidade de intermediação. Aguilar-Gallegos et al. (2016) trazem também a centralidade de Bonacich, de tal forma que os indicadores adotados podem variar de acordo com o foco de análise da pesquisa.

O tamanho da rede se refere à soma dos nós e pode interferir na disponibilidade ou limitação de recursos, bem como na dificuldade de construir ou manter relações e na capacidade de resolução de problemas. Já a densidade é a quantidade de relações existentes diante das possibilidades de relações (RIBEIRO; BASTOS, 2011).

Enquanto a distância geodésica é o menor número de relações entre um ator e outro da rede, a menor distância entre os atores, o diâmetro é a quantidade de passos entre os atores mais distantes da rede, por meio do qual é possível identificar o quão grande é a rede e quantas etapas são necessárias para que um conteúdo ou informação chegue de um lado para o outro (VIEIRA, 2008). Por meio do indicador de distância geodésica, pode-se inferir o grau de influência ou de coesão de uma rede, tendo em vista que, quanto maior a distância entre atores, menor será a influência de um sobre o outro, conforme explica Vieira (2008), ao citar Borgatti, Everett e Freeman (2000).

Ainda segundo Vieira (2008), o índice de coesão representa a interação entre os atores e indica o quanto a rede está compactada, bem como a reciprocidade de ligações. O autor se baseia nos estudos de Wasserman e Faust, 2006, para afirmar que, quanto maior for o índice de coesão entre os atores, mais eles serão afetados por padrões grupais e que, em redes mais coesas, os contatos são mais fortes, facilitando a comunicação, além de aumentar o compartilhamento de ideias, conceitos e crenças, o que pode gerar maior conformidade do pensamento grupal.

A centralidade de grau refere-se ao número de outros atores ao qual determinado ator está diretamente conectado por um vínculo, podendo ainda se identificar os graus de entrada, o número de indicação que um ator recebe de outros atores; e o grau de saída, que se refere ao número de indicações que o ator envia a outros atores (AGUILAR-GALLEGOS et al. 2016), referenciando-se em Freeman (1979), Ranneman e Riddle (2011), De Nooy et al. (2005) e Jackson (2008). Já a centralidade de intermediação refere-se ao grau em que um ator é ponte entre os demais atores (RIBEIRO; BASTOS, 2011; DE ROLT; DIAS; PEÑA, 2017). É a medida do controle exercido por determinado ator sobre as interações entre outros dois atores, "[...] mede, por exemplo, o número de vértices impactados com a saída de um determinado vértice" (DE ROLT; DIAS; PEÑA, 2017, p. 270).

Quanto à centralidade de Bonacich, Aguilar-Gallegos et al. (2016), referenciando-se em Bonacich (1987), explicam que o status de um ator dentro da rede se dá em função do status dos atores com os quais ele está conectado e que, para essa análise, utiliza-se um parâmetro que afeta o grau em que os vínculos distantes são considerados. Os autores explicam ainda que esse parâmetro pode atingir valores positivos ou negativos, indicando a centralidade de grau de um ator ou uma medida de poder, e que, quando esse parâmetro é zero, a medida é a centralidade de grau; todavia, se aumentar, os vínculos indiretos são mais relevantes. Pressupõe-se que esses vínculos indiretos são os vínculos passíveis de acesso por meio de intermediários, denotando a centralidade e o status do ator a partir de como estas se apresentam em suas relações. 
$\mathrm{Na}$ análise de redes, é possível identificar os atores com papéis críticos, como o expansor de fronteiras, o corretor de informações, além de características relacionais, como os cliques. Sendo assim, Alves (2016) faz referência a Neiva e Pantoja (2008) e Silva (2003), ao explicar que o expansor de fronteiras é o ator que conecta determinada rede a outras partes de uma rede ou a outras organizações. Para Alves (2016), um clique é um subgrupo coeso que faz escolhas mútuas e cujos indicadores podem ser utilizados na análise de coesão; já o corretor de informações, segundo Santos (2015), ao citar Costa (2003), é o ator que mantém a comunicação e que une os subgrupos de uma rede impedindo que ela se subdivida em partes ainda menores e menos eficientes.

Cabe ressaltar que existem outros indicadores utilizados na análise de redes, no entanto a escolha desses indicadores deve corresponder aos objetivos da pesquisa, de tal forma que, neste caso, serão analisados os que foram aqui apresentados.

\subsection{Redes informais interorganizacionais}

Como o próprio termo sugere, redes interorganizacionais são as redes formadas entre organizações. São arranjos formados por três ou mais organizações, públicas, privadas ou não governamentais que, para alcançar objetivos individuais e coletivos, colaboram entre si, mantendo sua autonomia e independência, como afirmam Roth, Antunes Junior e Padula (2012) referenciados em Hibbert, Huxham e Smith Ring, 2008; Provan e Kenis, 2008.

Powell et al. (2005 apud DE ROLT; DIAS; PEÑA, 2017) explicam que a rede interorganizacional se caracteriza por um padrão, passível de medida, de relações entre organizações em um ambiente social, onde normalmente as ações coletivas são fomentadas por fortes mudanças, quer seja de ordem social, quer seja de ordem econômica ou tecnológica.

Cunha, Passador e Passador (2012) explicam que as redes interorganizacionais carregam ranços do passado, de relações sociais e econômicas que sustentam e intermedeiam as suas relações, fato que as diferenciam das demais redes em termos de competitividade e estrutura social. Essa abordagem remete à dimensão temporal, também discutida por De Rolt, Dias e Peña (2017, p. 270), a qual afirmam ser uma dimensão essencial, visto que "[...] as relações são formadas por constantes mudanças de interesses e outras irregularidades".

A confiança, a aprendizagem e o conhecimento influenciam a competitividade das redes e das organizações participantes, uma vez que melhoram a flexibilidade, a velocidade e o tempo de chegada de um produto ou serviço diferenciado no mercado (ALVES et al., 2013). No entanto, segundo Estivalete, Pedrozo e Begnis (2012), nos casos de aprendizagem interorganizacional, por exemplo, a atuação em rede tanto poderá aumentar a vantagem competitiva, se houver simetria de aprendizagem, quanto poderá levar à perda de habilidades e diluição do conhecimento, se houver assimetria, uma vez que a assimetria no acesso ao processo de aprendizagem interorganizacional torna desigual a distribuição dos riscos e benefícios na relação.

Assim, Jordão (2015), ao citar Tomaél, 2005; Pelufê, 2005; Vallkokarim e Helander, 2007; Behr e Nascimento, 2008; Jardon e Martos, 2012 e 2014, afirma que o compartilhamento da informação é essencial para que as organizações melhorem a capacidade de gerar valor e de fomentar a aprendizagem organizacional. Peters et al. (2010 apud ESTIVALETE; PEDROZO; BEGNIS, 2012) afirmam que, entre as razões para que as empresas colaborem umas com as outras num ambiente competitivo, tem destaque a utilização do conhecimento coletivo a serviço de seus clientes, visando à maior efetividade, em que indústrias colaboram com os competidores a fim da agregação de valor por meio da aprendizagem coletiva. 
Por sua vez, Brito e Bastos (2001 apud GENARI; FACCIN; MACKE, 2013) afirmam que qualquer processo organizativo depende de uma relação de compromisso entre os atores acerca das metas, missão e valores da organização, e que o comprometimento é considerado um elemento estratégico, por possibilitar que as organizações enfrentem, com êxito, situações de mudança ou de turbulência no mercado. Corroborando essa ideia, Dyer e Chu (2003 apud KLEIN; PEREIRA, 2014) afirmam que o comprometimento e a confiança são capazes de criar um contexto colaborativo social propício ao compartilhamento de aprendizagem e informação e, referenciando-se em Lourenzani et al. (2006), complementam trazendo que o compromisso é condicionado pela confiança.

A formação de uma rede interorganizacional implica desafios, como a adoção de novas práticas contratuais, a gestão de conflitos de interesses entre os envolvidos, os custos iniciais para a implantação da rede e a implantação de modelos de gestão que delimitem a ação de cada agente (LUCARENA, 2010 apud DE ROLT; DIAS; PEÑA, 2017). Entretanto, uma vez que a rede consiga superar esses desafios, essa atuação em rede poderá servir de "vantagem competitiva sustentável", por combinar diferentes competências dos atores e gerar um diferencial competitivo, podendo transformar o produto proposto pela ação da rede, "relativamente insubstituível" (DE ROLT; DIAS; PEÑA, 2017, p. 268).

\section{METODOLOGIA}

O presente estudo pode ser considerado como descritivo, pois, segundo Gil (1996 apud ALVES et al., 2013), proporciona maior familiaridade com o assunto e aprimora concepções preexistentes. Tem caráter qualitativo e quantitativo. Pode ser classificado como um estudo de caso, que, segundo Laville e Dionne (1999), refere-se ao estudo de um caso específico, no qual, pela dedicação do pesquisador, oferece a oportunidade de aprofundamento, visto que poderá adaptar os instrumentos, modificar a abordagem para explorar elementos novos, entre outras possibilidades.

Inicialmente, empreendeu-se uma revisão bibliográfica nas bases de dados SciELO e no Google Acadêmico, utilizando os descritores: redes interorganizacionais, redes de cooperação, análise de redes, relações interorganizacionais, relações sociais interorganizacionais, agricultura familiar e desenvolvimento local. Foram priorizados artigos classificados entre os estratos A1-B1 do Qualis CAPES. Adicionalmente, analisaram-se os documentos disponíveis no sítio CSA BRASÍLIA, com o objetivo de levantar informações sobre a rede e identificar as CSAs existentes no DF até então. A pesquisa foi realizada entre janeiro e julho de 2019, período em que o Distrito Federal contava com 29 CSAs, e todas foram convidadas a responder ao questionário com o intuito de se obter uma melhor representação das redes.

Buscaram-se contatos por meio de e-mails, telefonemas e/ou mensagens de texto via aplicativo. A amostra compreendeu 23 CSAs, que foi o total de respondentes e que corresponde a $79,31 \%$ do universo pesquisado. As 23 CSAs analisadas envolviam aproximadamente 775 (setecentos e setenta e cinco) membros, considerando agricultores, coagricultores e organizadores, equivalendo a uma média de 33,69 pessoas por CSA, sendo 70 o maior número de membros, e o menor, 10. Observaram-se CSAs com cerca de dois meses de formação, e outras que já chegavam a quatro anos de experiência.

Foi utilizado um Termo de Consentimento Informado, resguardando as partes quanto a eventualidades. Para manter o anonimato do respondente, as CSAs foram nomeadas aleatoriamente utilizando o nome de algumas frutas ou vegetais cultivados pela agricultura familiar, resultando em uma lista que foi entregue ao participante da pesquisa juntamente de 
um questionário. A partir dos dados coletados, uma matriz quadrada foi gerada no Microsoft Excel e importada pelo software UCINET versão 6.681, para obtenção dos indicadores macro e microestruturais das redes. Por meio do NETDRAW, foi possível fazer a representação gráfica da rede. As CSAs que não participaram da pesquisa e que não foram indicadas por outras CSAs foram excluídas da análise.

\section{RESULTADOS E DISCUSSÕES}

\subsection{Caracterização das CSAs do Distrito Federal}

O movimento CSA foi introduzido no Distrito Federal em meados de 2012, a partir de experiências com grupos de amigos permacultores, que realizaram os primeiros plantios e diálogos sobre a implantação de uma CSA. Essa iniciativa foi sequenciada por uma palestra aberta no Centro de Desenvolvimento Sustentável, da Universidade de Brasília (UnB), em julho de 2014, com o tema: Exemplos de CSA na Europa: para além da lógica de mercado, e a participação de palestrantes da Alemanha, Philipp Weckenbrok, e da França, Cathy Boufafartique, promovida pelo Mutirão Agroflorestal (CSA BRASÍLIA, 2018).

Já em novembro de 2014, a CSA Demétria, localizada em Botucatu, São Paulo (SP), ofereceu o Curso de Implantação de CSA: Módulo Filosófico e Módulo Prático na CSA Demétria, Botucatu, SP, em que Fabiana Peneireiro, Renata Navega e Andrea Zimmermann, idealizadoras e articuladoras das CSAs no Distrito Federal, puderam participar e trazer as ideias do movimento para o DF. Logo em seguida, no mês de dezembro de 2014, iniciaram-se as articulações para a formação das primeiras CSAs do Distrito Federal, por meio de outra palestra no Centro de Desenvolvimento Sustentável, da UNB, com o tema Roda de Conversa sobre CSA: Partilha do Curso no CSA Demétria. Promoção: Mutirão Agroflorestal e Matres Socioambiental (CSA BRASÍLIA, 2018).

Em março de 2015, surgiram as primeiras CSAs no DF, a saber: CSA Toca da Coruja e CSA Barbetta, chegando a contar com 29 CSAs no momento desta pesquisa. Em abril de 2016, uma parceria entre a CSA Brasília, CSA Brasil, Matres Socioambiental e idealizadores da CSA Demétria trouxe a primeira formação em CSA para Brasília, realizada na Chácara Toca da Coruja (CSA BRASÍLIA, 2018).

Conforme CSA Brasília (2018), as CSAs do Distrito Federal têm como princípios e orientações, a saber: produção orgânica, local, sem intermediários; valorização da agricultura familiar; fortalecimento da agroecologia; gestão participativa, democrática e rotativa; cultivo de interações harmônicas; postura de corresponsabilidade; promoção do contato dos coagricultores com a terra; e incentivo à prática da economia associativa, tendo como valores: apoio mútuo, transparência, confiança, criatividade, diálogo, corresponsabilidade, solidariedade e integração.

\subsection{Rede de Compartilhamento de Conhecimentos, Informações, Ideias e Boas Práticas}

As medidas estruturais apontaram que, de um grupo de 23 respondentes, 28 atores foram citados, resultando uma rede de 115 laços, com 0,152 de densidade, ou seja, 15,2\% do potencial de ligações/relações estão sendo explorados; a distância geodésica, menor distância entre dois atores, resultou em 2,042 passos; o diâmetro, a maior distância para que um contato alcance outro contato da rede, foi de 7 passos; o índice de coesão foi de 27,5\% e a matriz simetrizada 
pelos mínimos, com o parâmetro mínimo de 3 atores por clique, resultou em 15 cliques de atores que se indicaram mutuamente.

Consideram-se atores centrais aqueles cujos graus de saída e de entrada normalizados são superiores à média desses indicadores, neste caso a média foi de 15,212\%, de tal maneira que foram identificados 7 conectores centrais, com destaque para: abacate, com a Centralidade de Bonacich = 2,147, sinalizando o seu poder na rede, e tomate-cereja, Bonacich =1,873.

Foram identificados 9 corretores de informação, com destaque para: tomate-cereja e mamão, com percentual de intermediação $=7,46 \%$ e 7,441\% respectivamente. Identificaram-se 3 expansores de fronteiras, aqueles que fazem a ligação de determinado ator ou rede a outros atores ou redes, a saber: berinjela, cebolinha e espinafre, cada um participando de 1 bloco, sendo que a saída desses atores pode fragilizar e diminuir o tamanho da rede.

O ator acelga chamou atenção, pois, mesmo não sendo considerado pela Centralidade de Grau de entrada e de saída um conector central, pela Centralidade de Bonacich revelou-se um ator com o segundo maior poder na Rede de Compartilhamento de Conhecimentos, Informações, Ideias e Boas Práticas = 2,106, corroborando o que dizem Aguilar-Gallegos et al. (2016), em que, ao referenciarem Bonacich, explicam que o status de um ator dentro da rede se dá em função do status dos atores com os quais ele está conectado.

Os atores mais críticos dessa rede eram: abacate, tomate-cereja e mamão, identificados como conectores centrais e corretores de informações; e cebolinha e espinafre, que exerciam simultaneamente os papéis de corretores de informação e expansores de fronteiras. Ressalta-se que, para Jordão (2015), o compartilhamento é essencial para que as organizações melhorem a capacidade de gerar valor e fomentar a aprendizagem organizacional.

Figura 1 - Mapa e papéis dos atores na rede de compartilhamento de conhecimento, informação, ideias e boas práticas

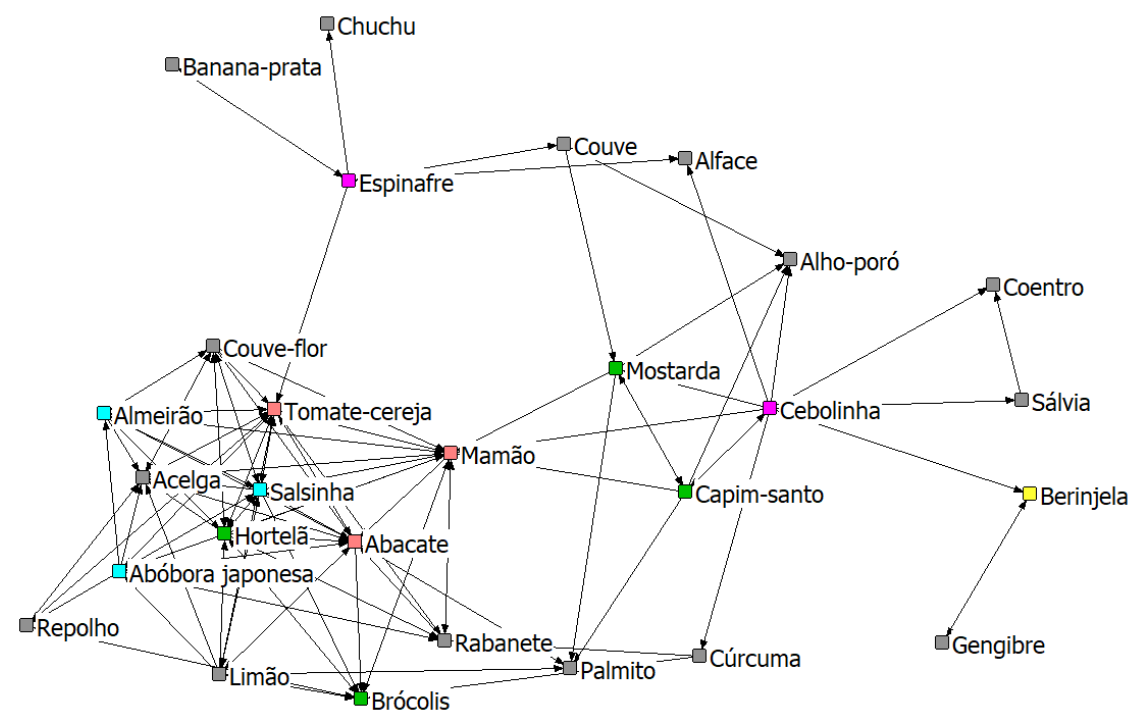

\footnotetext{
Atores sem papel central

$\square$ Conector central

$\square$ Corretor de informação

$\square$ Expansor de fronteiras

$\square$ Conector central e corretor de informação

$\square$ Corretor de informação e expansor de fronteiras
}

Fonte: Dados da pesquisa. 


\subsection{Rede de Comprometimento com os Princípios da CSA}

De um grupo de 23 respondentes, 28 atores foram citados. A rede apresentou 124 laços, com 0,164 de densidade, ou seja, $16,4 \%$ do potencial de relações estavam sendo explorados pela rede; a distância geodésica $=2,119$; o diâmetro = 5; por sua vez, o índice de coesão era de 35,7\%; e observou-se a existência de 39 cliques na Rede de Comprometimento com os Princípios da CSA. Foram encontrados 8 conectores centrais, destacando-se os atores: mamão, tendo indicado 9 atores e sendo indicado por 11, com Bonacich =2,025; e acelga, que indicou 9 atores, foi indicado por 8, com Bonacich =1,728.

Segundo Viera (2008), os atores que recebem mais indicações são mais prestigiados e importantes na rede, e os que indicam mais laços são mais habilidosos em acessar informações, recursos e compartilhar opiniões, configurando-se atores influentes na rede. Ressalta-se então que o ator hortelã recebeu 14 indicações, o maior número de indicações dessa rede, e indicou apenas 4 atores. No entanto possui Centralidade de Bonacich $=2,427$, um indicador maior que o dos demais atores, sinalizando para o seu potencial de influência na rede.

Foram identificados 10 corretores de informação, com destaque para: abacate, cujo percentual de intermediação foi $=14,9 \%$, tomate-cereja, $=11,6 \%$, e mamão $=10,8 \%$. E, como expansores de fronteiras, identificaram-se 3 atores, a saber: berinjela, coentro e mamão, cada um deles com participação em 1 bloco.

Os atores mais críticos dessa rede eram: abacate, abóbora japonesa, acelga, espinafre, mostarda, salsinha e tomate-cereja, identificados como conectores centrais e corretores de informações; berinjela, corretor de informação e expansor de fronteiras; e mamão, o mais crítico de todos, pois exercia simultaneamente os papéis de conector central, corretor de informação e expansor de fronteiras.

Ao buscar identificar os atores que exerciam papeis críticos simultaneamente em ambas as redes, verificou-se que os mais críticos eram: abacate - conector central e corretor de informações em ambas as redes; espinafre - corretor de informações e expansor de fronteiras na Rede de Compartilhamento de Conhecimentos, Informações, Ideias e Boas Práticas, e conector central e corretor de informações na Rede de Comprometimento com os Princípios da CSA; tomatecereja - conector central e corretor de informações em ambas as redes; e, por fim, mamão, o mais crítico, por acumular os papéis de conector central e corretor de informações na Rede de Compartilhamento de Conhecimentos, Informações, Ideias e Boas Práticas, e de conector central, corretor de informações e expansor de fronteiras na Rede de Comprometimento com os Princípios da CSA. 
Figura 2 - Mapa e papéis dos atores na rede de comprometimento com os princípios da CSA

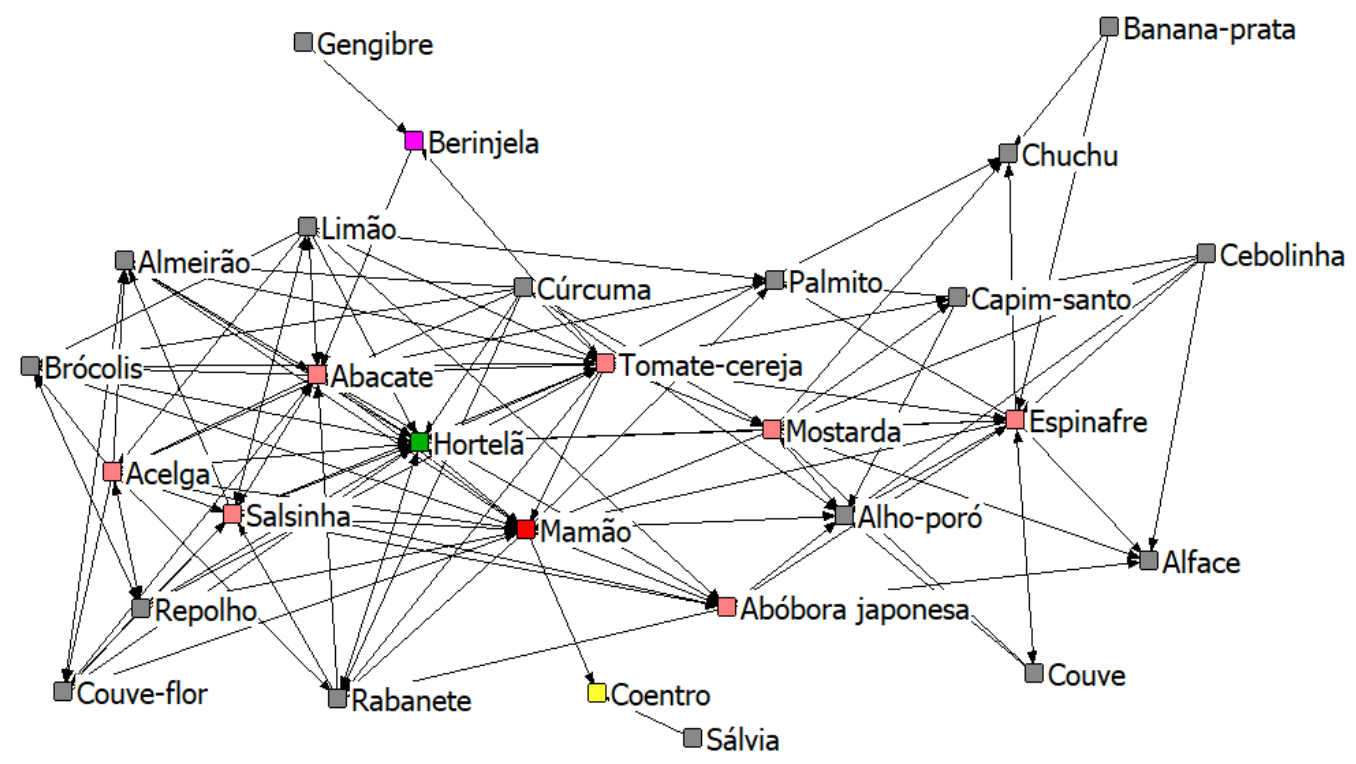

\footnotetext{
Atores sem papel central

$\square$ Conector central

$\square$ Corretor de informação

$\square$ Expansor de fronteiras

$\square$ Conector central e corretor de informação

$\square$ Corretor de informação e expansor de fronteiras

Conector central, corretor de informação e expansor de fronteiras
}

Fonte: Dados da pesquisa.

\section{CONSIDERAÇÕES FINAIS}

Verificou-se que alguns atores desempenhavam papéis críticos nas duas redes, a saber: abacate, espinafre, tomate-cereja e, por fim, mamão, o mais crítico, por acumular os papéis de conector central e corretor de informações na Rede de Compartilhamento de Conhecimentos, Informações, Ideias e Boas Práticas, e de conector central, corretor de informações e expansor de fronteiras na Rede de Comprometimento com os Princípios da CSA. Cabe ressaltar que uma alta centralidade pode tornar a rede vulnerável, pois, em caso de saída de um ator muito centralizado, muitos outros atores podem ser afetados (DE ROLT; DIAS; PEÑA, 2017).

Partindo do pressuposto de que ser referência na adoção dos princípios, nesse caso, é estar comprometido com o grupo, e que o comprometimento e a confiança podem influenciar no desenvolvimento de uma organização e no compartilhamento, admite-se neste trabalho que as CSAs referência são aquelas com maior centralidade e poder na Rede de Comprometimento com os Princípios da CSA, dado o número de indicações recebidas e o seu potencial em buscar contatos. Dessa forma, infere-se que a CSA Mamão era a principal referência para as demais, sinalizando para o seu comprometimento com os princípios de uma CSA, bem como para um considerável potencial de influenciar o grupo.

Infere-se que a Rede de Comprometimento com os Princípios da CSA pode influenciar na efetividade das relações entre as CSAs localizadas no DF, além de interferir nos processos colaborativos, de criação de novas CSAs, bem como no compartilhamento de conhecimentos, 
informações, ideias e boas práticas. Adicionalmente, podem influir no processo de inovação, na produtividade e no atendimento ao consumidor, que, no caso, são os coagrícultores. Permite-se inferir também que a coesão observada nas redes aqui pesquisadas pode estar relacionada ao tempo de funcionamento das unidades produtivas no modelo de CSA, em que se observou CSAs com cerca de dois meses de formação e outras com quatro anos.

Os índices de densidade e de coesão verificados parecem sinalizar, do ponto de vista das relações interorganizacionais, que o processo de consolidação da rede informal ainda se encontra em andamento. O surgimento de subgrupos pode estar relacionado à coesão das redes, podendo impactar na conformidade dos atores quanto aos padrões do grupo, pois, conforme Wasserman e Faust (2006 apud VIEIRA, 2008), quanto mais coesa for a rede, maior será a capacidade de comunicação devido à força dos laços recíprocos, fator que pode aumentar o compartilhamento e gerar conformidade grupal.

No entanto, considerando-se aspectos geográficos da distribuição das CSAs no Distrito Federal, que podem levar a uma maior ou menor fluidez dos contatos e do compartilhamento, e tendo em vista que se trata de organizações em que a autonomia e a independência são muito valorizadas, e não de pessoas em um departamento empresarial, por exemplo, onde as relações teoricamente deveriam ser mais fortes e coesas, torna-se plausível supor que haja conformidade do pensamento grupal acerca dos valores e princípios de uma CSA, especialmente na rede de comprometimento, a qual, mesmo sendo a rede com o maior número de subgrupos, foi também a que apresentou os maiores índices de densidade e coesão, levando a crer que a manutenção e o desenvolvimento do modelo produtivo de CSA no Distrito Federal pode ser uma alternativa viável para o desenvolvimento sustentável da agricultura familiar.

Acredita-se que este trabalho apresenta contribuições para a comunidade acadêmica, para gestores, agricultores, coagricultores e organizadores das CSAs do Distrito Federal, e àqueles que pretendem formar uma CSA como alternativa para as dificuldades inerentes à produção, comercialização, desenvolvimento e fortalecimento da agricultura familiar. Acredita-se também que este seja o primeiro estudo na literatura brasileira que buscou identificar, mapear e analisar as redes interorganizacionais das CSAs do Distrito Federal.

Uma das limitações desta pesquisa diz respeito à generalização dos resultados, por se tratar de um estudo de caso. Assim, as considerações e discussões aqui explanadas são de caráter explicativo e não pretendem formar opinião acerca das organizações estudadas, tampouco pretendem influenciar as relações e o processo decisório dessas organizações.

Os resultados aqui encontrados não exaurem as possibilidades de investigação, análise e compreensão das redes aqui exploradas. Novas pesquisas poderão ser realizadas abordando aspectos como a confiança, além de uma investigação das redes com uma maior envergadura, buscando envolver outros agentes, tais como comércios locais e órgãos públicos, onde se localizam os pontos de convivência das CSAs e empresas de assistência técnica, que podem estar envolvidos com as CSAs.

\section{REFERÊNCIAS}

AGUILAR-GALLEGOS, N.; MARTÍNEZ-GONZALEZ, E. G.; AGUILAR-ÁVILA, J.; SANTOYO-CORTÉS, H.; MUÑOZRODRÍGUES, M.; GARCÍA-SÁNCHES, E. I. Análisis de redes sociales para catalizar la innovación agrícola: de los vínculos directos a la integración y radialidad. Estudios Gerenciales, Cali, v. 32, n. 140, p. 197207, set. 2016. Disponível em: http://www.scielo.org.co/scielo.php?script=sci_arttext\&pid=S012359232016000300002\&lng=en\&nrm=iso. Acesso em: 24 jan. 2019. 
ALVES, R. A. Redes sociais no processo de gestão coletiva: o caso dos projetos de assentamento do programa nacional de crédito fundiário no município de Unaí - MG. 2016. 125 f. Dissertação (Mestrado em Agronegócios) - Universidade de Brasília, Brasília-DF, 2016. Disponível em: http://repositorio.unb.br/ handle/10482/20539. Acesso em: 12 jun. 2019.

ALVES, J. N.; PEREIRA, B. A. D.; ANDRADE, T.; REIS, E. Confiança, aprendizagem e conhecimento nos relacionamentos interorganizacionais: diagnóstico e análise dos avanços sobre o tema. REAd: Revista Eletrônica de Administração, Porto Alegre, v. 19, n. 3, p. 709-37, 2013. Disponível em: http://www. scielo.br/scielo.php?script=sci_arttext\&pid=S1413-23112013000300007\&lng=en\&nrm=iso. Acesso em: 29 jan. 2019.

ASATO, T. A.; MARqueS, H. R.; BUZARquIS, R. M; BORGES, P. P. Perspectivas da economia criativa e do desenvolvimento local no corredor bioceânico. Interações, Campo Grande, v. 20, n. especial, p. 193-210, 2019. Disponível em: http://www.scielo.br/scielo.php?script=sci_arttext\&pid=S151870122019000500193\&lng=en\&nrm=iso. Acesso em: 9 abr. 2020. doi: https://doi.org/10.20435/inter. v20iespecial.2559

BRASIL. Ministério do Desenvolvimento Agrário. Plano safra 2017/2020. Brasília-DF: MDA, 2018. Disponível em: http://www4.planalto.gov.br/consea/eventos/plenarias/apresentacoes/2017/plano-safra-daagriocultura-familiar-2017-2020-secretaria-especial-de-agricultura-familar-e-desenvolvimento-agrario4a-plenaria-27-de-setembro-de-2017.pdf/view\#acontent. Acesso em: 7 jan. 2019.

COMUNIDADE QUE SUSTENTA A AGRICULTURA [CSA]. CSA Brasil, 2015. Comunidades que sustentam a agricultura: da cultura do preço para a cultura do apreço. Disponível em: http://csabrasil.org. Acesso em: 4 jan. 2019.

COMUNIDADE QUE SUSTENTA A AGRICULTURA EM BRASÍLIA [CSA BRASÍLIA]. CSA Brasília, 2018. Comunidades que sustentam a agricultura: da cultura do preço para a cultura do apreço. Disponível em: https://csabrasilia.wordpress.com. Acesso em: 19 jan. 2019.

CONFEDERAÇÃO NACIONAL DOS TRABALHADORES E TRABALHADORAS NA AGRICULTURA FAMILIAR DO BRASIL [CONTRAF-BRASIL]. Contraf Brasil, 2018. Agricultura familiar. Disponível em: https://contrafbrasil. org.br. Acesso em: 5 jan. 2019.

CUNHA, J. A. C.; PASSADOR, J. L.; PASSADOR, C. S. A presença de agentes intermediadores na formação de redes interorganizacionais: uma análise sob a perspectiva temporal. Cadernos EBAPE.BR, Rio de Janeiro, $v$. 10, n. 1, p. 108-28, 2012. Disponível em: http://www.scielo.br/scielo.php?script=sci_arttext\&pid=S167939512012000100008\&lng=en\&nrm=iso. Acesso em: 28 jan. 2019.

DE ROLT, C. R.; DIAS, J. S.; PEÑA, F. T. G. Análise de redes como ferramenta de gestão para empreendimentos interorganizacionais. Gestão \& Produção, São Carlos, v. 24, n. 2, p. 266-78, 2017. Disponível em: http:// www.scielo.br/scielo.php?script=sci_arttext\&pid=S0104-530X2017000200266\&lng=en\&nrm=iso. Acesso em: 4 jan. 2019.

DORSA, A. C. Desenvolvimento local e processos participativos. Interações, Campo Grande, v. 20, n. 1, p. 1-2, 2019. Disponível em http://www.scielo.br/scielo.php?script=sci_arttext\&pid=S151870122019000100001\&lng=en\&nrm=iso. Acesso em: 9 abr. 2020. doi: https://doi.org/10.20435/inter. v20i1.2444

ESTIVALETE, V. F. B; PEDROZO, E. A; BEGNIS, H. S. M. O processo de aprendizagem em redes horizontais do elo varejista do agronegócio: uma análise sob a perspectiva das estratégias, dos métodos e dos estágios evolutivos. REAd: Revista Eletrônica de Administração, Porto Alegre, v. 18, n. 1, p. 161-90, 2012. Disponível em: http://www.scielo.br/scielo.php?script=sci_arttext\&pid=S1413-23112012000100006\&ln $\mathrm{g}=$ en\&nrm=iso. Acesso em: 27 jan. 2019. 
GENARI, D.; FACCIN, K.; MACKE, J. Mensuração do comprometimento organizacional em redes de indústrias vitivinícolas brasileiras. REAd: Revista Eletrônica de Administração, Porto Alegre, v. 19, n. 2, p. 351-83, 2013. Disponível em: http://www.scielo.br/scielo.php?script=sci_arttext\&pid=S141323112013000200004\&lng=en\&nrm=iso. Acesso em: 19 jan. 2019.

GUANZIROLI, C. E; BUAINAIN, A. M; DI SABBATO, A. Dez anos de evolução da agricultura familiar no Brasil: (1996 e 2006). Revista de Economia e Sociologia Rural, Brasília, v. 50, n. 2, p. 351-70, 2012. Disponível em: http://www.scielo.br/scielo.php?script=sci_arttext\&pid=S0103-20032012000200009\&lng=en\&nr m=iso. Acesso em: 1o fev. 2019.

JORDÃO, R. V. D. Práticas de gestão da informação e do conhecimento em pequenas e médias empresas organizadas em rede: um estudo multicasos na indústria brasileira. Perspectivas em Ciências da Informação, Belo Horizonte, v. 20, n. 3, p. 178-99, set. 2015. Disponível em: http://www.scielo.br/scielo. php?script=sci_arttext\&pid=S1413-99362015000300178\&lng=en\&nrm=iso. Acesso em: 18 jan. 2019.

KLEIN, L. L.; PEREIRA, B. A. D. Contribuições para a gestão de redes interorganizacionais: fatores determinantes para a saída de empresas parceiras. REAd: Revista Eletrônica de Administração, Porto Alegre, v. 20, n. 2, p. 305-40, 2014. Disponível em: http://www.scielo.br/scielo.php?script=sci_arttext\&pid=S1413$23112014000200305 \&$ Ing=en\&nrm=iso. Acesso em: 4 fev. 2019.

LAVILLE, C.; DIONNE, J. A construção do saber: manual de metodologia da pesquisa em ciências humanas. Adaptação da obra de Lana Mara Siman. Porto Alegre: Artmed, 1999.

MARTINS, A. L. B. Agricultura apoiada pela comunidade ou comunidade apoiada pela agricultura? A relação campo-cidade pela ética da solidariedade. 2017. 413 f. Tese (Doutorado em Geografia) - Universidade Federal Fluminense, Niterói, RJ, 2017.

NEIVA, E. R.; PANTOJA, M. J. Redes sociais e mudança em um grupo de produtores rurais do planalto central. Revista Psicologia: Organizações e Trabalho, Florianópolis, v. 8, n. 1, p. 5-24, dez. 2008. Disponível em: https://periodicos.ufsc.br/index.php/rpot/article/view/9067. Acesso em: 5 jan. 2019.

OLIVEIRA, B. G.; LIBONI, L. B. Proposta de indicador de eficiência da gestão pública municipal em promover desenvolvimento local. Interações, Campo Grande, v. 20, n. 3, p. 815-30, 2019. Disponível em: http:// www.scielo.br/scielo.php?script=sci_arttext\&pid=S1518-70122019000300815\&lng=en\&nrm=iso. Acesso em: 9 abr. 2020. doi: https://doi.org/10.20435/inter.v0i0.1831

PADUA, J. B.; SCHLINDWEIN, M. M.; GOMES, E. P. Agricultura familiar e produção orgânica: uma análise comparativa considerando os dados dos censos de 1996 e 2006. Interações, Campo Grande, v. 14, n. 2, p. 225-35, 2013. Disponível em: http://www.scielo.br/scielo.php?script=sci_arttext\&pid=S151870122013000200009\&Ing=en\&nrm=iso. Acesso em: 1ㅇ Fev. 2019.

RIBEIRO, E. M. B. de A.; BASTOS, A. V. B. Redes sociais interorganizacionais na efetivação de projetos sociais. Psicologia \& Sociedade, Florianópolis, v. 23, n. 2, p. 282-92, ago. 2011. Disponível em: http:// www.scielo.br/scielo.php?script=sci_arttext\&pid=S0102-71822011000200009\&lng=en\&nrm=iso. Acesso em: 18 jan. 2019.

ROTH, A. L.; WEGNER, D.; ANTUNES JUNIOR, J. A. V.; PADULA, A. D. Diferenças e inter-relações dos conceitos de governança e gestão de redes horizontais de empresas: contribuições para o campo de estudos. Revista de Administração, São Paulo, v. 47, n. 1, p. 112-23, 2012. Disponível em: http://www.scielo.br/scielo. php?script=sci_arttext\&pid=S0080-21072012000100009\&Ing=en\&nrm=iso. Acesso em: 18 jan. 2019.

SANTOS, V. G. Configurações das redes sociais de uma associação em diferentes períodos da gestão. 2015. 69 f. Monografia (Graduação em Gestão de Agronegócios) - Universidade de Brasília, Brasília-DF, 
2015. Disponível em: http://bdm.unb.br/bitstream/10483/17166/1/2015_ValeriaGomesdosSantos_tcc. pdf. Acesso em: 12 jun. 2019.

VERANO, T. C.; MEDINA, G. S. Comercialização por agricultores familiares em feiras municipais: quantificação, participação, e localização no estado de Goiás. Interações, Campo Grande, v. 20, n. 4, p. 1045-56, 2019. Disponível em: http://www.scielo.br/scielo.php?script=sci_arttext\&pid=S1518-70122019000401045\&ln g=en\&nrm=iso. Acesso em: 9 abr. 2020. doi: https://doi.org/10.20435/inter.v20i4.1984

VIEIRA, S. R. F. Redes sociais no contexto de mudança organizacional. 2008. 133 f. Dissertação (Mestrado em Psicologia Social, do Trabalho e das Organizações) - Universidade de Brasília, Brasília-DF, 2008. Disponível em: http://repositorio.unb.br/handle/10482/8316. Acesso em: 1o jan. 2019.

\section{Sobre os autores:}

Joelma Melo da Silva: Mestranda em Agronegócios na Universidade de Brasília (UnB). Bacharela em Gestão de Agronegócios pela UnB. E-mail: joelmamelo.unb@gmail.com, Orcid: https://orcid.org/0000-0002-5049-9343

Maria Júlia Pantoja: Doutora em Psicologia Organizacional e do Trabalho pela Universidade de Brasília (UnB). Mestra e graduada em Psicologia pela UnB. Professora associada da UnB, com atuação nos programas de pós-graduação em Agronegócios, Faculdade de Agronomia e Medicina Veterinária; e Gestão Pública, Faculdade de Economia, Administração, Contabilidade e Gestão de Políticas Públicas (FACE)/UnB. E-mail: jpantoja@unb.br, Orcid: http://orcid.org/0000-0002-6533-7240

Sergio Ricardo Franco Vieira: Mestre em Psicologia Social, Organizacional e do Trabalho pela Universidade de Brasília (UnB). Graduado em Psicologia pela Universidade Federal da Bahia (UFBA). E-mail: sergiopsi1975@gmail.com, Orcid: http://orcid.org/0000-0003-3421-3250 
